\title{
Modification Effect of Nano-Graphene Oxide on Properties and Structure of Polysulfone Ultrafiltration Membrane
}

\author{
Hao Yuan, Lahua Jin, Dan Luo, Chen Ge \\ School of Environment, Jinan University, Guangzhou, China \\ Email: profjin@163.com
}

How to cite this paper: Yuan, H., Jin, L.H., Luo, D. and Ge, C. (2018) Modification Effect of Nano-Graphene Oxide on Properties and Structure of Polysulfone Ultrafiltration Membrane. Journal of Environmental Protection, 9, 1185-1195. https://doi.org/10.4236/jep.2018.911074

Received: September 21, 2018

Accepted: October 26, 2018

Published: October 29, 2018

Copyright ( 92018 by authors and Scientific Research Publishing Inc. This work is licensed under the Creative Commons Attribution International License (CC BY 4.0).

http://creativecommons.org/licenses/by/4.0/

\begin{abstract}
In order to improve the purification properties of polysulfone (PSF) ultrafiltration membranes (UFM), nano-graphene oxide (nano-GO) was taken as modifier, and the physical blending process was adopted in our experiment. The microstructure, surface morphology and functional groups of modified UFM have been characterized respectively by scanning electron microscopy, atomic force microscopy and Fourier transform infrared spectroscopy, and the static contact angle between the membrane surface and the water droplet has also been detected to show the change of its hydrophilicity. Through experiments, it has been found that modified UFM has larger and more developed finger micro-pores, and there exist a large number of -OH groups on its surface, and also its hydrophilicity has been enhanced. The result of the experiments show that the modified UFM may keep rejection above $97 \%$ and its water flux can be reached at about $219.1 \mathrm{~L} /\left(\mathrm{m}^{2} \cdot \mathrm{h}\right)$ under pressure of 1 bar if $0.4 \mathrm{wt} \%$ of nano-GO was added. Additionally, the nano-GO can increase the flux recovery radio (FRR) of the membranes, and the maximum FRR was observed as $74.4 \%$ if $0.3 \mathrm{wt} \%$ of nano-GO was appended.
\end{abstract}

\section{Keywords}

Nano-Graphene Oxide, Ultrafiltration Membrane, Polysulfone, Water Purification

\section{Introduction}

The membrane separation technology has been widely adopted in concentration [1] and purification [2], seawater desalination [3], wastewater treatment [4] and other fields due to its compact equipment and easy automation. As membrane 
performance and structure play a crucial role during the separation process, it becomes one of research focuses of membrane separation technology to develop new separation membranes with excellent performance and available structure.

Polysulfone (PSF) has been widely used in producing separation membranes due to its high temperature, anti-oxidation and acid resistance [5], but it has strong hydrophobicity. Usually, pure PSF membranes behave as low water flux, fouling problem and short life. In order to overcome these draw-backs, some improving measures have been experimental studied these years, such as nano-metallic oxides $\left(\mathrm{TiO}_{2}\right.$ [6], $\mathrm{SiO}_{2}$ [7], $\mathrm{Al}_{2} \mathrm{O}_{3}$ [8], $\mathrm{ZnO}$ [9], $\mathrm{ZrO}_{2}$ [10], $\mathrm{Fe}_{3} \mathrm{O}_{4}$ [11]) and low dimensional carbon nano-material (graphite oxide and carbon nanotubes [12]) have been found to be most helpful to improve membrane performances if blending with polymers, where graphene oxide (GO) has been gotten more attention because of its high surface area, strong hydrophilicity [13], antibacterial ability [14] and the characteristic of negative charge in whole $\mathrm{pH}$ range [15].

In order to improve PSF membrane hydrophilicity and anti-fouling properties, a new PSF ultrafiltration membrane (UFM) has been fabricated out in our experiments by taking nano-GO as modifier and immersion precipitation phase inversion method, and the surface morphology and microstructure of UFM were observed and its separation performance was also studied.

\section{Materials and Methods}

\subsection{Experimental Materials}

The materials prepared for membrane fabrication include PSF (P-1700, Industrial Grade), polyvinyl pyrrolidone (PVP, K-30, AR), N, N-dimethylacetamide (DMAc, AR), nano-GO (nominal size $0.1-0.2 \mu \mathrm{m}$ ) and bovine serum albumin (BSA, MV $=67,000, \mathrm{BR}$ ). All reagents were analytical grade and used as received without further purification.

\subsection{Preparation of the Membranes}

Pure PSF UFM and modified UFM were prepared by the phase inversion process method. All materials were dried in a vacuum oven at $80^{\circ} \mathrm{C}$ for 24 hours to remove adsorbed water before the preparation. The procedure for the preparation of membrane is as follows.

At first, add different weight addition ratio of nano-GO (such as $0,0.1,0.2$, $0.3,0.4,0.5$ and $0.75 \mathrm{wt} \%)$ and about $2 \mathrm{wt} \%$ of PVP into the DMAc solvent, and disperse the mixed solution for 90 minutes with an ultrasonicator.

Secondarily, dissolve $20 \mathrm{wt} \%$ of PSF in the solution, and continuously stir the solution for 8 hours under the condition of $70^{\circ} \mathrm{C}$ temperature. Afterwards, we can obtain homogeneous modified PSF casting solution without air bubbles.

Thirdly, prepare a clean glass plate for casting membrane, and pour the casting solution onto the plate, and then carefully scrape the solution to the designed area on it to form a uniform thickness membrane with a single-sided film appli- 
cator of $200 \mu \mathrm{m}$ thick.

At last, let the membrane with the plate expose to air for $20 \mathrm{~s}$, and immerse them into the distilled water with temperature of $25^{\circ} \mathrm{C}$ until the membrane is completely detached from the plate, and then place it into pure water for 24 hours in order to remove all residual solvents or porogen. Afterwards, the modified PSF UFM is obtained, and they were labeled as M-0, M-1, M-2, M-3, M-4, M-5 and M-6 respectively corresponding to its nano-GO content appended, where $\mathrm{M}-0$ represents pure PSF membrane.

\subsection{Methods of Detection and Analyses}

The microstructure of the cross section of the membrane was observed by a scanning electron microscopy (EV MA15, Zeiss), but all specimens were coated with a thin layer of gold before observation. In order to analyze the surface morphology and obtain surface roughness parameters of membranes, 3D surface images were prepared by Atomic Force Microscopy (AFM bioscope catalyst nanoscope-V, Bruker), and the scanning area was $5 \mu \mathrm{m} \times 5 \mu \mathrm{m}$. The curved surface of droplet on membranes was photographed by the contact angle/interfacial tension meter (SL200KB, Coro), and then the contact angle between the droplet and the membrane surface can be calculated out. The membrane porosity $\mathcal{E}(\%)$ was determined by the gravimetric method, and its mean pore size was calculated out with the Guerout-Elford-Ferry Equation on the basis of the flux and porosity [6].

The permeation flux of the UFM were measured by a self-made cross-flow filtration device with $19.64 \mathrm{~cm}^{2}$ of membrane effective area under the pressure of 1 bar after the device had been run over 30 min under the pressure of 1.5 bar in order to remove remaining chemical substances.

The pollutant rejection rate of the UFM was expressed as its removal rate of bovine serum albumin (BSA), which was determined by the relative difference between raw water concentration and outlet concentration of BSA from the UFM. The raw water concentration of BSA was designed as $1000 \mathrm{mg} / \mathrm{L}$ during our experiments, but the outlet concentration was detected by sampling and analyzed with an UV-visible spectrophotometer (UV-1800, Shimad-zu) at 280 nm.

The flux recovery rate (FRR) of the UFM was defined as the ratio of the water flux of the UFM which has been washed with distilled water for $15 \mathrm{~min}$ after it had been adopted to filtrate the BSA aqueous solution of $1000 \mathrm{mg} / \mathrm{L}$ for $30 \mathrm{~min}$ to the water flux of the UFM before it was adopted to filtrate the BSA aqueous solution. FRR can reflect the antifouling property of the UFM. The flux, rejection and FRR were calculated according to the literature [6].

\section{Results and Analyses}

\subsection{Functional Group Characterization of Membranes}

The FT-IR spectrum of membranes with nano-GO content was characterized as 
shown in Figure 1.

It can be found from Figure 1 that the UFM has typical spectra of PSF, in which the peak at $2968 \mathrm{~cm}^{-1}$ and the peak at $2872 \mathrm{~cm}^{-1}$ are respectively attributed to the asymmetric stretching vibration (ASSV) and symmetric stretching vibration (SSV) of C-H in $-\mathrm{CH}_{3}$, and the peaks at $1294 \mathrm{~cm}^{-1}$ and at $1151 \mathrm{~cm}^{-1}$ are the absorption peaks at ASSV and SSV of sulfone group $(\mathrm{O}=\mathrm{S}=\mathrm{O})$ respectively, but the peak at $1242 \mathrm{~cm}^{-1}$ is the ASSV absorption peak of aromatic ether in PSF. Moreover, peaks at $1585 \mathrm{~cm}^{-1}, 1504 \mathrm{~cm}^{-1}$ and $1489 \mathrm{~cm}^{-1}$ are due to stretching vibration of benzene ring skeleton, and the peak at $1716 \mathrm{~cm}^{-1}$ is assigned to the stretching vibrations of $\mathrm{C}=\mathrm{O}$ in the carbonyl group.

It can be obtained the regular features from Figure 1 that, comparing with pure PSF membrane, the UFM has a strong and wide absorption peak at 3422 $\mathrm{cm}^{-1}$, which corresponds to the tensile vibration of $\mathrm{O}-\mathrm{H}$, and its intensity and width may increase with the increase of the nano-GO content.

It can be proved from above that nano-GO can be well dispersed in the UFM and its surface hydrophilicity has been obviously improved.

\subsection{Morphology of Membranes}

The cross section SEM images of the UFM with different nano-GO contents were observed as shown in Figure 2. It can be found from Figure 2 that all the membranes, apart from M-6, exhibit characteristic asymmetric structure of dense top layer followed by fingerlike support layer, and the inner walls of the fingerlike pores were filled with sponge pores. Normally, pure PSF often displayed a flatter and denser top layer, but the modified UFM presented larger fingerlike pores, more developed lateral pore structure that allow the fingerlike pores to communicate with each other [16]. These differences may be caused by the hydrophilic nature of nano-GO which could lead to improve thermodynamic

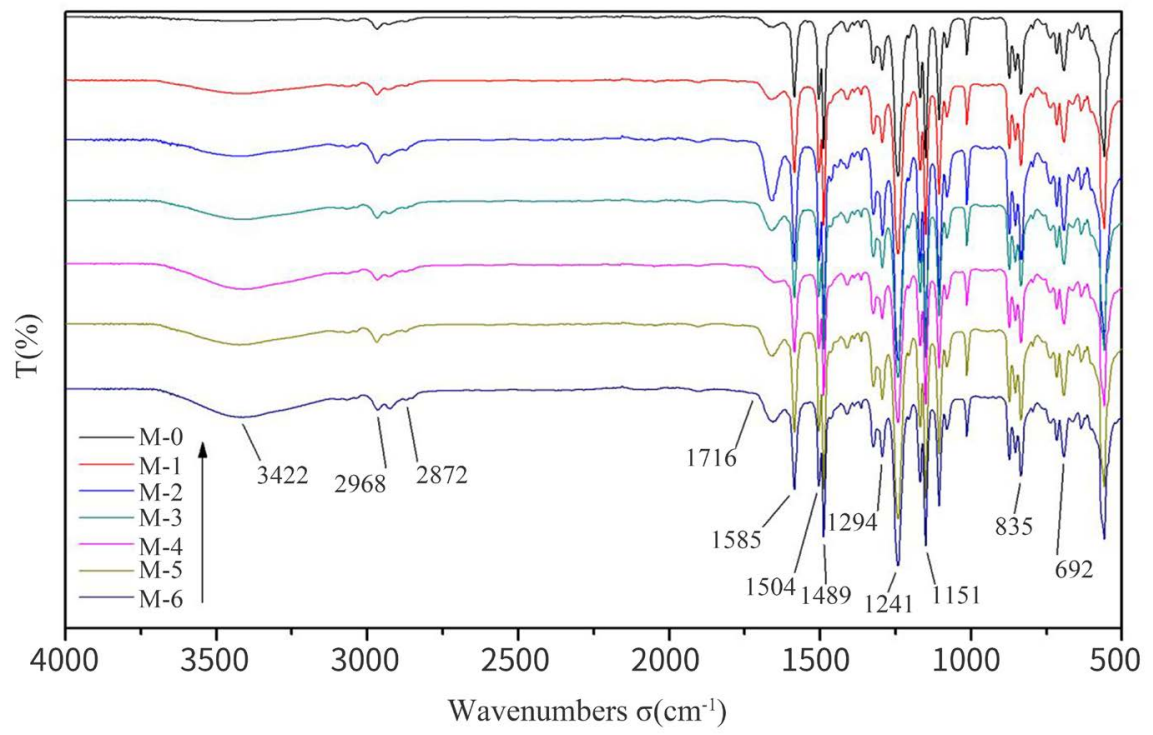

Figure 1. Stacked ATR-FTIR spectra of membranes. 


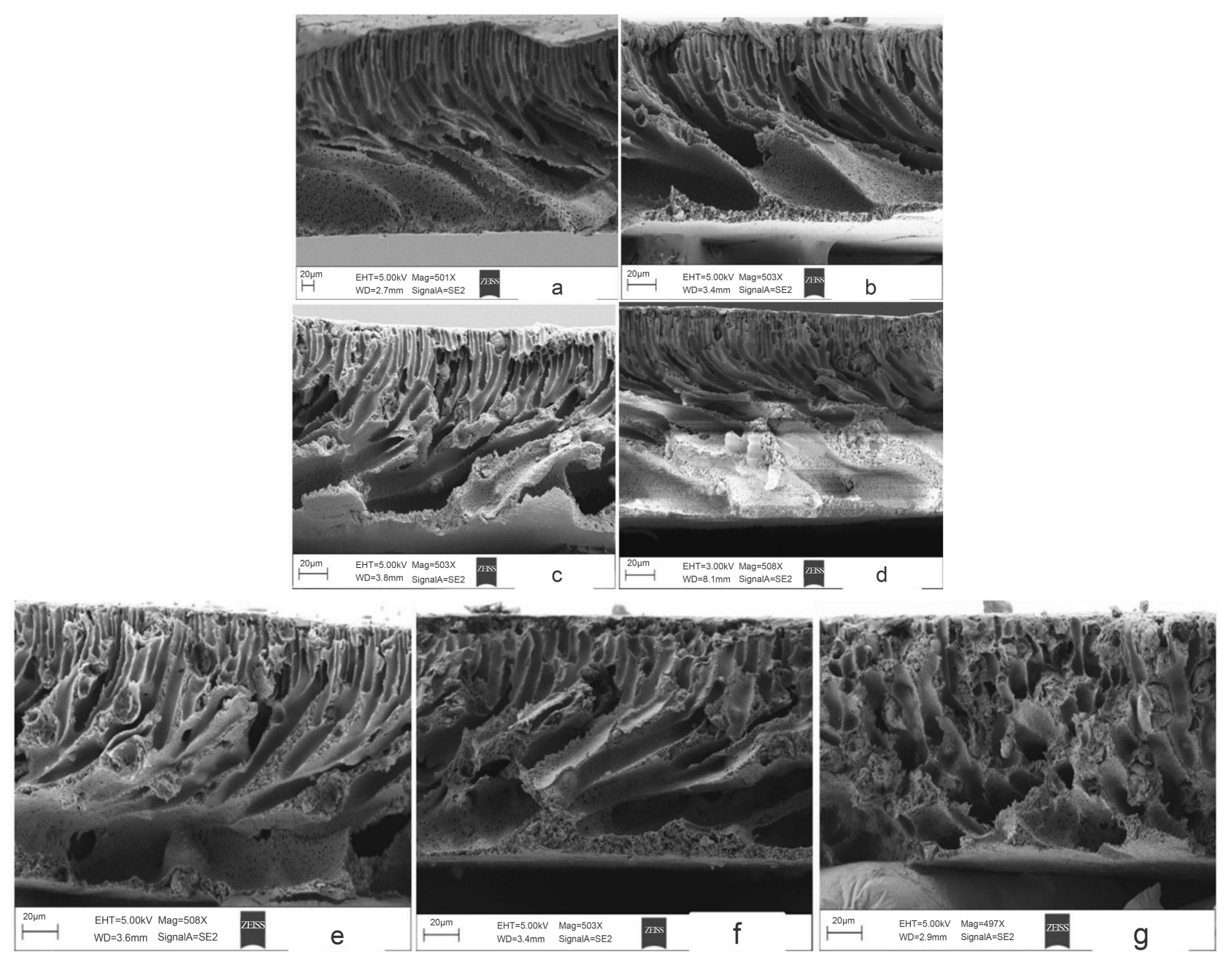

Figure 2. Cross sectional SEM images of membranes. (a) M-0; (b) M-1; (c) M-2; (d) M-3; (e) M-4; (f) M-5; (g) M-6.

instability of the casting solution and to accelerate the mass transfer rate between the solvent and the non-solvent during phase inversion, which facilitate the growth of macro-porous structures [17]. In addition, when the quantity of the nano-GO reaches a certain level, there are nano-GO aggregates inside membranes and the finger structure gradually weakens and changes to the irregular micro-porous structure.

The 3D AFM surface image of the UFM were obtained as shown in Figure 3, and the different roughness parameters of the UFM was calculated out as shown in Table 1. It can be seen from Figure 3 and Table 1 that the surface of pure PSF UFM presents a large number of "peaks" and "valleys", and its mean roughness reaches $24.0 \mathrm{~nm}$, but as to the modified UFM the altitude intercept between the "peak" and the "valley" was obviously reduced, which means its surface is smooth.

It has been found during our experiments that the roughness of the modified UFM appended nano-GO more than $0.3 \mathrm{wt} \%$ becomes bigger, which may be led by the agglomeration of nanomaterials on the surface of membranes [18] and the formation of voids or nodules due to the mass transfer rate [19]. 

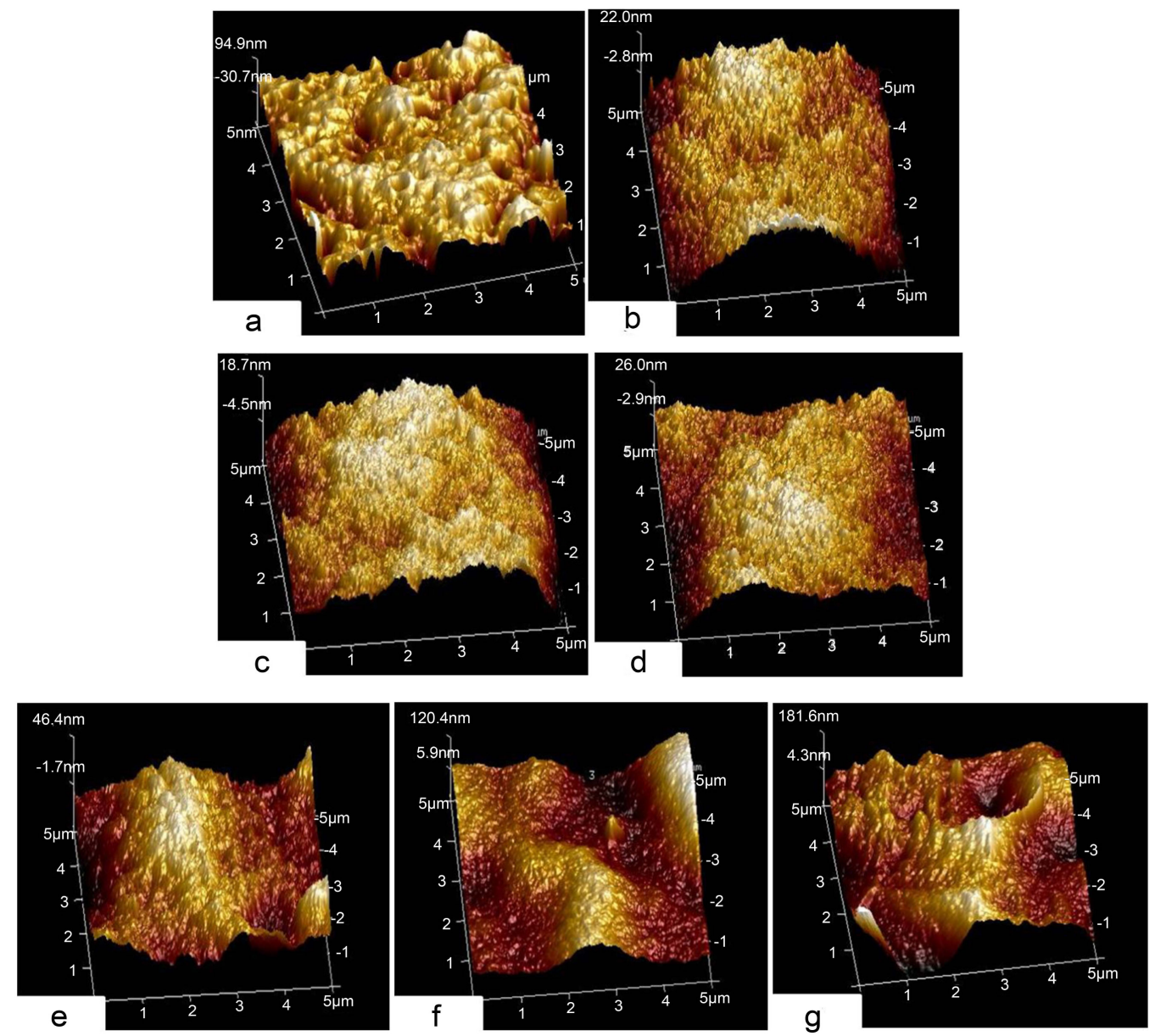

Figure 3. AFM images of membranes. (a) M-0; (b) M-1; (c) M-2; (d) M-3; (e) M-4; (f) M-5; (g) M-6.

Table 1. Surface roughness parameters and contact angle

\begin{tabular}{ccc}
\hline UFM label & $\begin{array}{c}\text { Roughness } \\
(\mathrm{nm})\end{array}$ & $\begin{array}{c}\text { Contact angle } \\
(\mathrm{deg})\end{array}$ \\
\hline M-0 & 24.0 & $76.38 \pm 0.69$ \\
M-1 & 7.0 & $70.96 \pm 1.41$ \\
M-2 & 5.3 & $70.77 \pm 0.66$ \\
M-3 & 5.3 & $69.05 \pm 0.6$ \\
M-4 & 6.3 & $69.63 \pm 0.42$ \\
M-5 & 25.1 & $68.99 \pm 1.41$ \\
M-6 & 39.4 & $69.97 \pm 0.30$ \\
\hline
\end{tabular}

\subsection{Porosity and Pore Size of Membrane}

It has been observed that with increase of nano-GO content appended, the porosity and mean pore radius of the modified UFM increase from $76.3 \%$ and 20.9 $\mathrm{nm}$ to $80.1 \%$ and $32.3 \mathrm{~nm}$ respectively if the nano-GO content is less than 0.4 $\mathrm{wt} \%$, but decreased otherwise (Figure 4). The phenomenon may is attributed to hydrophilicity of nano-GO which results in transient phase transformation, and 


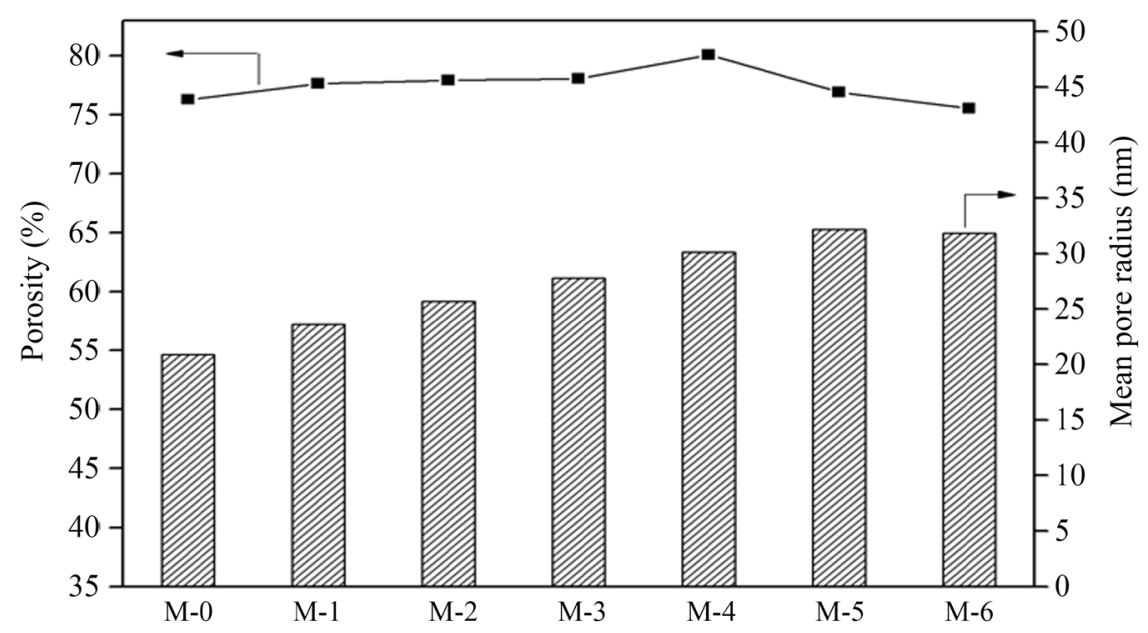

Figure 4. Mean pore radius and porosity of membranes.

consequently large pores are formed, but excess nano-GO increases the viscosity of casting solution, which is not conducive to diffusion between the solvent and the non-solvent, so the pore structure is inhibited [20]. Moreover, blocking part of the pores by nano-GO agglomerates is one of the reasons for the decrease in porosity.

\subsection{Hydrophilicity of Membranes}

The water contact angle (CA) of the UFM was detected as shown in Table 1. CA can be used to represent the hydrophilicity of the membrane.

It can be found from Table 1 that the UFM CA decreases from $76.4^{\circ}$ to $69.1^{\circ}$ with the increase of the nano-GO content appended from $0 \%$ to $0.3 \mathrm{wt} \%$, which proves that the surface hydrophilicity of the UFM has been improved, and higher nano-GO content appended has no significant effect to improve the CA, this is coordinated with the absorption peak of -OH in the FT-IR spectrum as shown in Figure 1. In the initial stage of phase inversion, nano-GO migrates spontaneously to the top surface of the membrane due to its strong hydrophilicity, which leads to decrease CA. An overdose of nano-GO renders agglomeration on the surface of the UFM due to steric hindrance and mutual electrostatic interaction, which reduce the effective area of the nano-material, so the hydrophilicity of the UFM increases no longer [21].

\subsection{Pure Water Flux and Rejection of Membranes}

The results of water flux and rejection of the UFM was obtained as shown in Figure 5.

It has been shown by Figure 5 that the water flux of pure PSF UFM is only 98.7 $\mathrm{L} /\left(\mathrm{m}^{2} \cdot \mathrm{h}\right)$ under pressure of 1 bar, the smallest flux among flux of all UFM, and the flux of modified UFM becomes greater and greater with the increase of the content of nano-GO appended. As the content arrives at $0.4 \mathrm{wt} \%$ or above, the flux almost keeps steady about $219.1 \mathrm{~L} /\left(\mathrm{m}^{2} \cdot \mathrm{h}\right)$ under pressure of $1 \mathrm{bar}$, which 


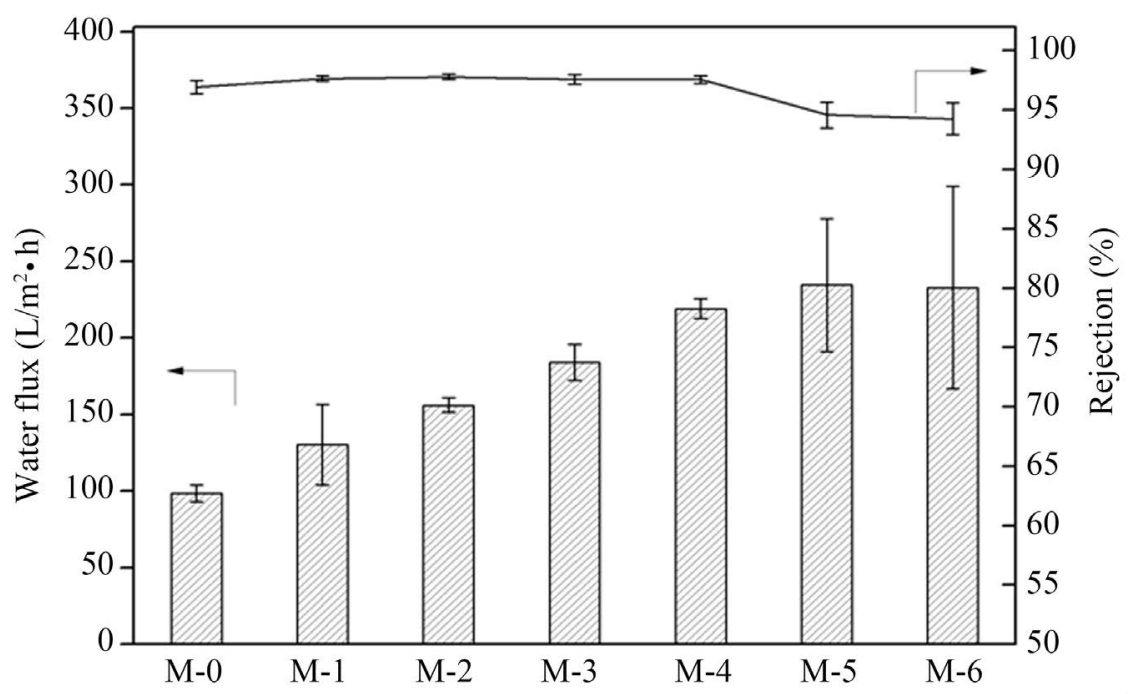

Figure 5. Water permeation flux and BSA rejection of membranes.

is 2.2 times of those of the pure PSF UFM. This shows that the increase of water flux is not due to the defects and cracks in the dense cortex at the top of the membrane [22], but due to enhanced hydrophilicity and improved internal pore structure. At the same time, the rejection of the UFM keeps at about $97 \%$ if the content of nano-GO appended is not above $0.4 \mathrm{wt} \%$, but slightly lower if the content exceeds $0.4 \mathrm{wt} \%$, as shown in Figure 5, which may be caused by non-selective cracks or defects with uneven distribution on the membrane.

\subsection{Antifouling Properties of Membranes}

The flux recovery rate of the UFM was shown in Figure 6. The higher the FRR value, the better the antifouling performance of the UFM. Obviously, the modified UFM had higher FRR values than those of pure PSF UFM, and the FRR shows a similar trend to the hydrophilicity trend and surface roughness of membranes. This showed that the FRR obtains the highest value of $74.4 \%$ when the content of nano-GO arrives at $0.3 \mathrm{wt} \%$. It is generally assumed that hydrophilic groups on membrane surface adsorb water molecules to form water layers, which make hydrophobic substance adhere difficultly to membrane due to the steric-hindrance effect [23]. Moreover, the roughness also plays an important role on the antifouling property.

The smoother the UFM surface is, the more difficult it is for protein molecules to adhere. In high loading of nano-GO, due to the rougher surface, hydrophobic substance such as protein can accumulate easily in the "valley" [24], resulting in a decrease of the FRR value and weakening of the antifouling property.

\section{Conclusions}

Nano-GO can be uniformly dispersed to the PSF casting solution by physical blending process, and the PSF UFM has been prepared with immersion precipitation phase inversion technology. 


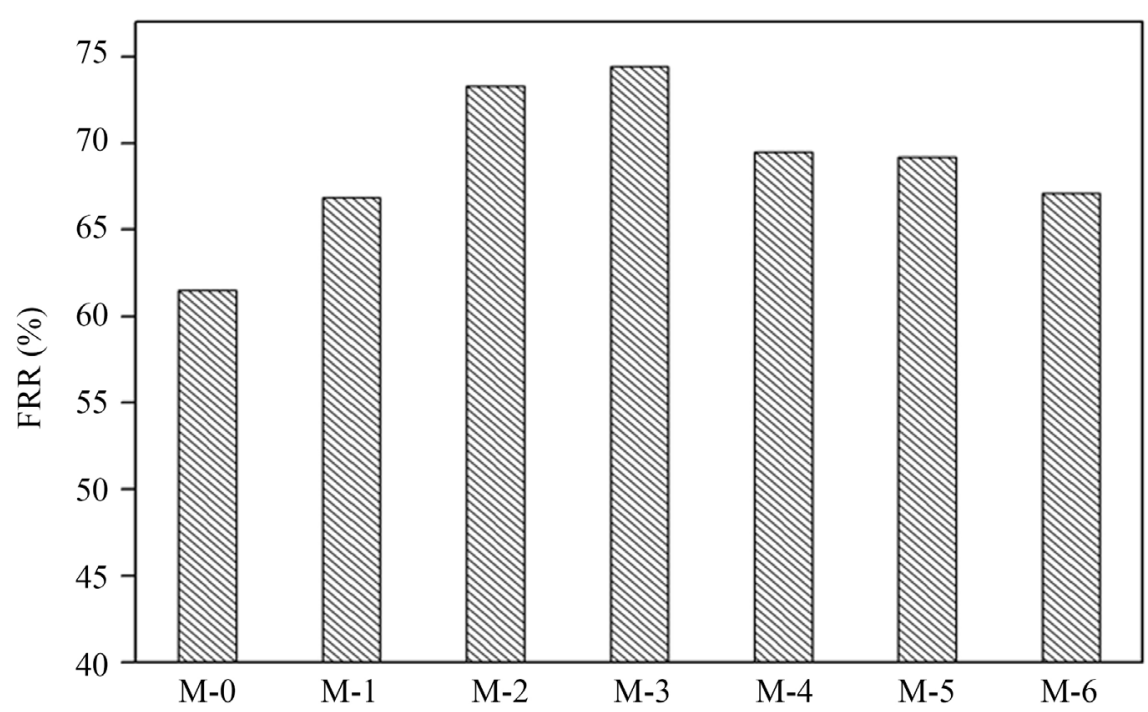

Figure 6. Effect of nano-GO content on flux recovery ratio.

The hydrophilic property, permeability and antifouling property of the UFM can be obviously improved if hydrophilic groups such as $-\mathrm{OH}$ and $-\mathrm{COOH}$ on nano-GO are successfully loaded onto the surface of the UFM.

The doping of nano-GO could modify morphology of the UFM so that the porosity may be increased, the average pore radius of the finger pores may be enlarged and the connectivity among the finger pores can be enhanced.

Compared with pure PSF UFM, the modified UFM has stronger hydrophilic property, higher water flux and better antifouling ability, but keeps almost the same rejection.

\section{Acknowledgements}

This study is funded by the Water Resource Science and Technology Innovation Program of Guangdong Province (2017-27).

\section{Conflicts of Interest}

The authors declare no conflicts of interest regarding the publication of this paper.

\section{References}

[1] Mistry, V.V. and Maubois, J.L. (2004) Application of Membrane Separation Technology to Cheese Production. Cheese Chemistry Physics \& Microbiology, 1, 261-285. https://doi.org/10.1016/S1874-558X(04)80070-8

[2] Saleh, J., Tremblay, A.Y. and Dubé, M.A. (2010) Glycerol Removal from Biodiesel Using Membrane Separation Technology. Fuel, 89, 2260-2266. https://doi.org/10.1016/j.fuel.2010.04.025

[3] Matsuura, T. (2001) Progress in Membrane Science and Technology for Seawater Desalination-A Review. Desalination, 134, 47-54. https://doi.org/10.1016/S0011-9164(01)00114-X

[4] Lee, C.W., Bae, S.D., Han, S.W. and Kang, L.S. (2007) Application of Ultrafiltration 
Hybrid Membrane Processes for Reuse of Secondary Effluent. Desalination, 202, 239-246. https://doi.org/10.1016/j.desal.2005.12.059

[5] Yunos, M.Z., Harun, Z., Basri, H. and Ismail, A.F. (2014) Studies on Fouling by Natural Organic Matter (NOM) on Polysulfone Membranes: Effect of Polyethylene Glycol (PEG). Desalination, 333, 36-44. https://doi.org/10.1016/j.desal.2013.11.019

[6] Vatanpour, V., Madaeni, S.S., Khataee, A.R., Salehi, E., Zinadini, S. and Monfared, H.A. (2012) $\mathrm{TiO}_{2}$ Embedded Mixed Matrix PES Nanocomposite Membranes: Influence of Different Sizes and Types of Nanoparticles on Antifouling and Performance. Desalination, 292, 19-29. https://doi.org/10.1016/j.desal.2012.02.006

[7] Han, L.F., Xu, Z.L., Cao, Y., Wei, Y.M. and Xu, H.T. (2011) Preparation, Characterization and Permeation Property of $\mathrm{Al}_{2} \mathrm{O}_{3}, \mathrm{Al}_{2} \mathrm{O}_{3}-\mathrm{SiO}_{2}$ and $\mathrm{Al}_{2} \mathrm{O}_{3}$-Kaolin Hollow Fiber Membranes. Journal of Membrane Science, 372, 154-164.

https://doi.org/10.1016/j.memsci.2011.01.065

[8] Lu, Y., Yu, S.L., Chai, B.X. and Xianda, S. (2006) Effect of Nano-Sized $\mathrm{Al}_{2} \mathrm{O}_{3}$-Particle Addition on PVDF Ultrafiltration Membrane Performance. Journal of Membrane Science, 276, 162-167. https://doi.org/10.1016/j.memsci.2005.09.044

[9] Liang, S., Xiao, K., Mo, Y. and Huang, X. (2012) A Novel ZnO Nanoparticle Blended Polyvinylidene Fluoride Membrane for Anti-Irreversible Fouling. Journal of Membrane Science, 394-395, 184-192. https://doi.org/10.1016/j.memsci.2011.12.040

[10] Arthanareeswaran, G. and Thanikaivelan, P. (2010) Fabrication of Cellulose Acetate-Zirconia Hybrid Membranes for Ultrafiltration Applications: Performance, Structure and Fouling Analysis. Separation \& Purification Technology, 74, 230-235. https://doi.org/10.1016/j.seppur.2010.06.010

[11] Huang, Z.Q., Zheng, F., Zhang, Z., Xu, H.T. and Zhou, K.M. (2012) Performance of the PVDF- $\mathrm{Fe}_{3} \mathrm{O}_{4}$ Ultrafiltration Membrane and the Effect of a Parallel Magnetic Field Used during the Membrane Formation. Desalination, 292, 64-72.

https://doi.org/10.1016/j.desal.2012.02.010

[12] Zhao, Y., Xu, Z., Shan, M., Min, C., Zhou, B., Li, Y. and Qian, X. (2013) Effect of Graphite Oxide and Multi-Walled Carbon Nanotubes on the Microstructure and Performance of PVDF Membranes. Separation and Purification Technology, 103, 78-83. https://doi.org/10.1016/j.seppur.2012.10.012

[13] Kuilla, T., Bhadra, S., Yao, D., Kim, N.H., Bose, S. and Lee, J.H. (2010) Recent Advances in Graphene Based Polymer Composites. Progress in Polymer Science, 35, 1350-1375. https://doi.org/10.1016/j.progpolymsci.2010.07.005

[14] Akhavan, O. and Ghaderi, E. (2010) Toxicity of Graphene and Graphene Oxide Nanowalls against Bacteria. Acs Nano, 4, 5731-5736. https://doi.org/10.1021/nn101390x

[15] Szabó, T., Tombácz, E., Illés, E. and Dékány, I. (2006) Enhanced Acidity and pH-Dependent Surface Charge Characterization of Successively Oxidized Graphite Oxides. Carbon, 44, 537-545. https://doi.org/10.1016/j.carbon.2005.08.005

[16] Wang, Z., Yu, H., Xia, J., Zhang, F., Li, F., Xia, Y. and Li, Y. (2012) Novel GOBlended PVDF Ultrafiltration Membranes. Desalination, 299, 50-54. https://doi.org/10.1016/j.desal.2012.05.015

[17] Vatanpour, V., Madaeni, S.S., Moradian, R., Zinadini, S. and Astinchap, B. (2012) Novel Antibifouling Nanofiltration Polyethersulfone Membrane Fabricated from Embedding $\mathrm{TiO}_{2}$ Coated Multiwalled Carbon Nanotubes. Separation \& Purification Technology, 90, 69-82. https://doi.org/10.1016/j.seppur.2012.02.014

[18] Lau, W.J., Ismail, A.F., Goh, P.S., Hilal, N. and Ooi, B.S. (2015) Characterization 
Methods of Thin Film Composite Nanofiltration Membranes. Separation \& Purification Methods, 44, 135-156. https://doi.org/10.1080/15422119.2014.882355

[19] Ganesh, B.M., Isloor, A.M. and Ismail, A.F. (2013) Enhanced Hydrophilicity and Salt Rejection Study of Graphene Oxide-Polysulfone Mixed Matrix Membrane. Desalination, 313, 199-207. https://doi.org/10.1016/j.desal.2012.11.037

[20] Yuliwati, E. and Ismail, A.F. (2011) Effect of Additives Concentration on the Surface Properties and Performance of PVDF Ultrafiltration Membranes for Refinery Produced Wastewater Treatment. Desalination, 273, 226-234. https://doi.org/10.1016/j.desal.2010.11.023

[21] Vatanpour, V., Madaeni, S.S., Moradian, R., Zinadini, S. and Astinchap, B. (2011) Fabrication and Characterization of Novel Antifouling Nanofiltration Membrane Prepared from Oxidized Multiwalled Carbon Nanotube/Polyethersulfone Nanocomposite. Journal of Membrane Science, 375, 284-294.

https://doi.org/10.1016/j.memsci.2011.03.055

[22] Zinadini, S., Zinatizadeh, A.A., Rahimi, M., Vatanpour, V. and Zangeneh, H. (2014) Preparation of a Novel Antifouling Mixed Matrix PES Membrane by Embedding Graphene Oxide Nanoplates. Journal of Membrane Science, 453, 292-301. https://doi.org/10.1016/j.memsci.2013.10.070

[23] Wang, C., Feng, R. and Yang, F. (2011) Enhancing the Hydrophilic and Antifouling Properties of Polypropylene Nonwoven Fabric Membranes by the Grafting of Poly (N-vinyl-2-pyrrolidone) via the ATRP Method. Journal of Colloid \& Interface Science, 357, 273. https://doi.org/10.1016/j.jcis.2011.01.094

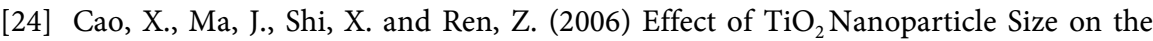
Performance of PVDF Membrane. Applied Surface Science, 253, 2003-2010. https://doi.org/10.1016/j.apsusc.2006.03.090 